\title{
Leiomiossarcoma epitelióide mediastinal em paciente portador de insuficiência coronária: tratamento cirúrgico simultâneo
}

\author{
Luís Alberto DALLAN, Sérgio Almeida de OLIVEIRA*, Raimunda Violante ASSIS*, Léa Macruz SILVA*, \\ José Carlos R. IGLÉZIAS*, Geraldo VERGINELLI*, Adib D. JATENE*
}

DALLAN, L. A.; OLIVEIRA, S. A.; ASSIS, R. V.; SILVA, L. M.; IGLÉZIAS, J.C.R.; VERGINELLI, G.; JATENE, A.D. - Leiomiossarcoma epitelióide mediastinal em paciente portador de insuficiência coronária: tratamento cirúrgico simultâneo. Rev. Bras. Cir. Cardiovasc., 6(3):213-219, 1991.

RESUMO: É descrito o caso de uma paciente portadora de angina há quatro anos, que se instabilizou nos últimos seis meses. Foi submetida a revascularizaçāo do miocárdio, através da realização de enxertos de artéria esquerda e de duas pontes de veia safena, além da ressecção de massa mediastinal, cujo exame histológico revelou leiomiossarcoma epitelióide. A paciente fora histerectomizada há 13 anos, e o diagnóstico radiológico precoce do tumor foi dificultado devido a paquipleuriz e a fibroses torácicas decorrentes de tuberculose pulmonar e de toracotomia prévia. Destacamos a raridade dessa associaçāo e a validade do procedimento cirúrgico simultâneo.

DESCRITORES: miocárdio, revascularização + tumor de mediastino, cirurgias simultâneas; miocárdio, revascularização, cirurgia; tumores de mediastino, cirurgia.

\section{INTRODUÇÄO}

Os tumores mediastinais apresentam baixa incidência na prática clínica diária e seu crescimento silencioso dificulta o diagnóstico precoce. Sua concomitância com coronariopatia isquêmica constitui um fato incomum, e a presença de angina contribui, ainda mais, para que o cardiologista não - inclua como uma provável hipótese diagnóstica associada.

Os leiomiossarcomas têm origem na musculatura lisa, especialmente uterina, podendo levar, tardiamente, a metástases por via sangüínea. Quando detectados em fase inical, sua ressecção, associada à extirpação de seu sítio primário, proporcionam a cura do paciente.

Descrevemos o caso de uma paciente de 64 anos, com antecedentes de tuberculose pulmonar $e$ ressecção de mioma uterino (sic) há 13 anos, na qual foi possível, num único ato cirúrgico, a ressecção de tumor mediastinal e a revascularização do miocárdio, com sucesso.

\section{RELATO DO CASO}

Paciente de 64 anos, branca, sexo feminino,

Trabalho realizado no Instituto do Coração do Hospital das Clínicas da Faculdade de Medicina da Universidade de São Paulo. São Paulo, SP, Brasil. Recebido para publicação em 11 de dezembro de 1991.

*Do Instituto do Coração do Hospital das Clínicas da Faculdade de Medidicina da Universidade de São Paulo.

Endereço para separatas: Luís Alberto Dallan. Av. Dr. Enéas de Carvalho Aguiar, 44. Divisão Cirúrgica. 05403 São Paulo, SP, Brasil. 
DALLAN, L. A.; OLIVEIRA, S. A.; ASSIS, R. V.; SILVA, L. M.; IGLÉZIAS, J.C.R.; VERGINELLI, G.; JATENE, A.D. - Leiomiossarcoma epitelióide mediastinal em paciente portador de insuficiência coronária: tratamento cirúrgico simultâneo. Rev. Bras. Cir. Cardiovasc., 6(3):213-219, 1991.

com queixa de dor precordial em opressão, desencadeada aos mínimos esforços, irradiada para ombro esquerdo e associada a dispnéia e palpitaçōes. Esses sintomas iniciaram-se há quatro anos e aumentaram de intensidade e freqüência nos últimos seis meses, apesar de medicada com digitálicos, diuréticos, coronariodilatadores e antiarrítmicos. Nesse período, passou também a apresentar edema de membros inferiores.

Como antecedente importante, destacava-se a ocorrência de tuberculose pulmonar na adolescência, tendo recebido tratamento específico e sido submetida a toracotomia esquerda.

Referia, também, histerectomia há 13 anos, para retirada de tumor uterino (mioma; sic).

Ao exame físico, constatamos hipertensão arterial ( $160 \times 110 \mathrm{~mm} \mathrm{Hg}$ ), obesidade, estase jugular, diminuição da expansibilidade e do murmúrio vesicular em hemitórax esquerdo. A ausculta cardíaca encontrava-se dentro dos limites da normalidade, não sendo detectados sopros ou arritmias.

Aos RX simples de tórax, notava-se imagem mais densa, localizada em mediastino anterior, com cerca de $10 \mathrm{~cm}$ de diâmetro e contornos pouco definidos, que se confundia com o hilo pulmonar direito (Figura 1). Observava-se, ainda, retração e

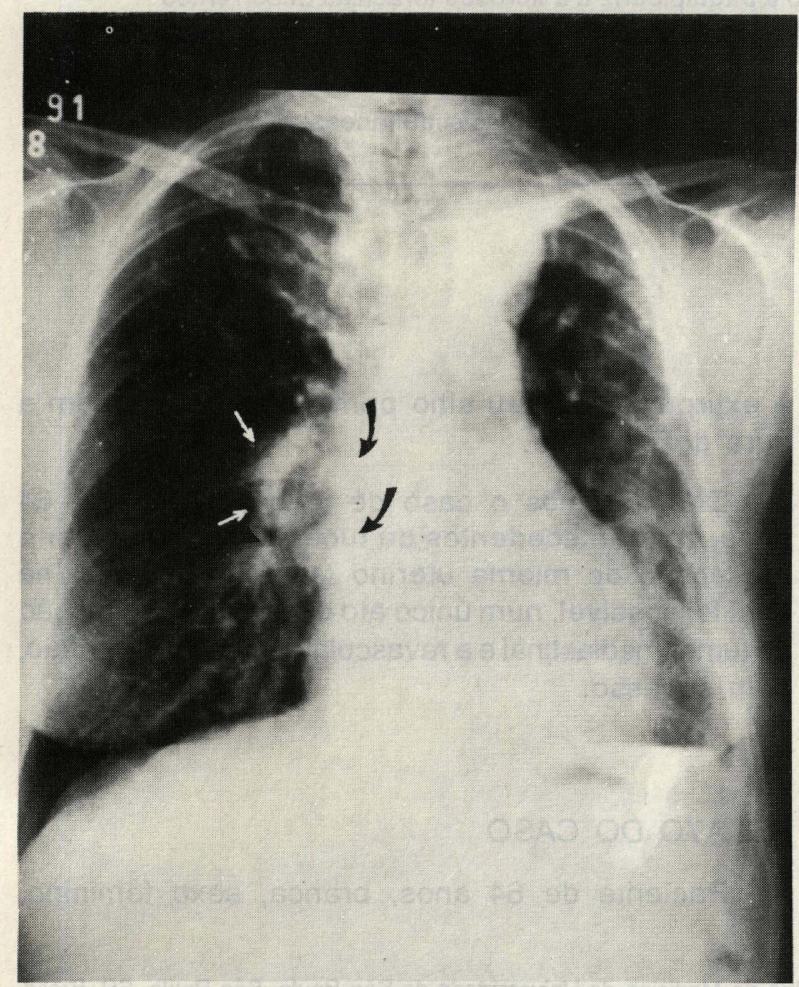

Fig. 1 - RX de toráx P-A pré-operatório, notando-se paquipleuriz em HTE (Tbc) e massa tumoral mediastinal de contornos pouco definidos. fibrose em hemitoráx esquerdo, como seqüelas de tuberculose e de toracotomia prévias. A prova de função pulmonar revelou insuficiência respiratória restritiva grau III.

O eletrocardiograma apresentava sinais de sobrecarga ventricular esquerda e de fibrose de parede inferior, possivelmente decorrente de episódio anginoso prolongado ocorrido há seis meses.

O exame cinecoronariográfico demonstrou comprometimento triarterial severo, com função ventricular esquerda preservada (Figuras 2 e 3).

A paciente foi revascularizada com o auxílio da circulação extracorpórea, tendo sido realizada anastomose da artéria mamária interna esquerda para artéria descendente anterior e pontes com veia safena para as artérias coronária direita e marginal esquerda. No mesmo ato cirúrgico, foi ressecado o tumor que se encontrava na região mediastinal anterior, pouco aderido às estruturas subjacentes, o que possibilitou sua completa remoção (Figura 4). O estudo imuno-histoquímico da peça resultou negativo para marcadores de fibra muscular (HHF-35 e Desmina). Entretanto, o aspecto histológico típico observado, sugerindo neoplasia constituída por células fusiformes ou ovais, de citoplasma claro e núcleo vesiculoso, permitiu o diagnóstico de leiomiossarcoma epitelióide (Figura 5).

A paciente teve boa evolução imediata, apresentando, como única intercorrência pós-operatória, um episódio de flutter atrial, que regrediu espontaneamente, obtendo alta hospitalar no $12^{\circ} \mathrm{dia}$. Novas investigações pélvicas e torácicas vêm sendo realizadas periodicamente, visando prevenir recidivas tumorais.

\section{COMENTÁRIOS}

Os tumores do mediastino constituem, com freqüência, achados ocasionais, não só por sua raridade, mas, especialmente, pela pobreza de sintomas que proporcionam em sua fase inicial.

Isso também ocorreu no caso da paciente que descrevemos, uma vez que as manifestaçōes clínicas da coronariopatia mascararam os possíveis sintomas decorrentes do crescimento do tumor. Soma-se a isso a tuberculose pulmonar que a paciente apresentou na adolescência. A retração do hemitórax esquerdo, conseqüente à fibrose pulmonar e à toracotomia a que foi submetida, alteraram a silhueta mediastinal habitualmente observada nas radiografias de toráx, fazendo com que o tumor passasse desapercebido por muitos anos.

O leiomiossarcoma se origina da musculatura lisa, e sua sede preferencial é o útero. Outras lo- 
DALLAN, L. A.; OLIVEIRA, S. A.; ASSIS, R. V.; SILVA, L. M.; IGLÉZIAS, J.C.R.; VERGINELLI, G.; JATENE, A.D. - Leiomiossarcoma epitelióide mediastinal em paciente portador de insuficiência coronária: tratamento cirúrgico simultâneo. Rev. Bras. Cir. Cardiovasc., 6(3):213-219, 1991.

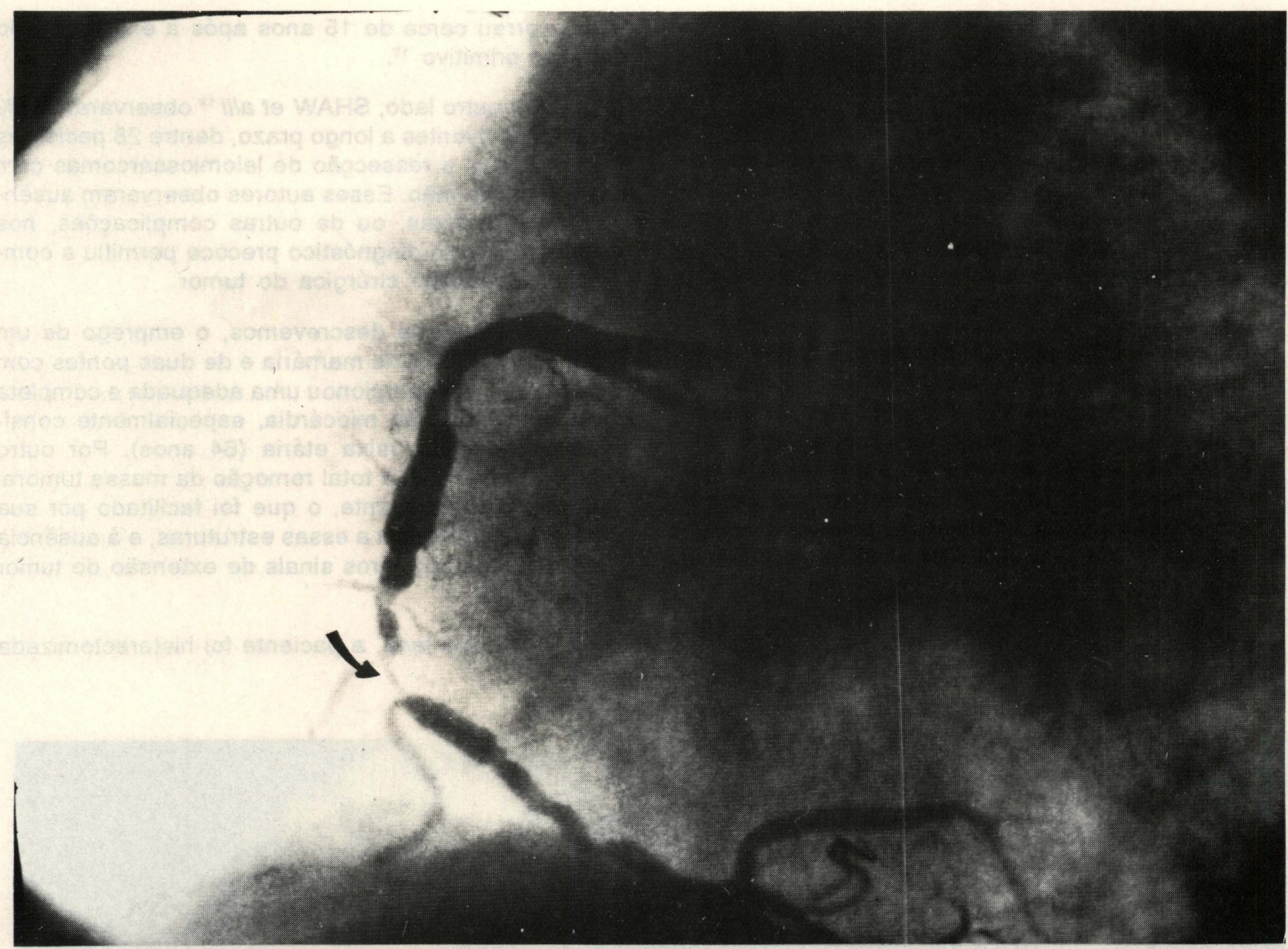

Fig 2. - Artéria coronária direita com lesão suboclusiva em seu terço-médio (seta).

calizaçöes como parede intestinal, fígado ou, mesmo, mediastino são raras e, em geral, decorrem de metástases por via sangüínea ${ }^{\circledR}$. Leiomiossarcomas localizados no coração podem também ser confundidos com outras doenças cardiácas, mimetizando sintomas cardiocirculatórios, como dispnéia e palpitaçōes 1,7,8. Quando de localização pulmonar, podem apresentar imagem radiológica cística ${ }^{5}$ ou abscedada ${ }^{13}$, o que, igualmente, dificulta seu diagnóstico e posterga sua extirpação cirúrgica.

O leiomiossarcoma de tecidos moles também é raro ${ }^{2}$. Sua incidência é predominante em indivíduos adultos, embora tenham sido descritos alguns casos em crianças ${ }^{4}$. A maioria desses tumores localiza-se em extremidades, especialmente em paredes de veias e artérias de diferentes calibres. Em ordem de freqüência, destacam-se a veia cava inferior, veia safena, veia femoral, artéria pulmonar femoral e aorta ${ }^{4}$.

Seu tipo de crescimento é, predominantemente, fascicular, podendo, à semelhança do leiomioma, ser bem circunscrito, embora, freqüentemente, desenvolva necrose, hemorragia ou degeneração cística ${ }^{10}$.

Os núcleos celulares do leiomiossarcoma tendem a ser alongados e com disposição paralela uns aos outros, o que os assemelha aos tumores nervosos periféricos. O grau de atipia nuclear é, também, bastante variável e, em casos extremos, pode ser confundido com o histiocitoma fibroso maligno 10. O citoplasma da célula tumoral pode apresentar granulação focal, assim como degeneraçōes mixóides proeminentes ${ }^{11}$. Sob o aspecto ultraestrutural, o tumor exibe células com numerosos filamentos citoplasmáticos com densidades focais, vesículas de pinocitose e membrana basal fina ${ }^{6}$.

Imuno-histoquimicamente, tanto o leiomioma como - leiomiossarcoma bem diferenciado podem mostrar reatividade por actina, miosina, desmina e componentes da lâmina basal, incluindo lâminina e colágeno tipo IV ${ }^{3}$.

O diagnóstico diferencial entre leiomioma e leiomiossarcoma depende da combinação de seu 
DALLAN, L. A.; OLIVEIRA, S. A.; ASSIS, R. V.; SILVA, L. M.; IGLÉZIAS, J.C.R.; VERGINELLI, G.; JATENE, A.D. - LeiomiosSarcoma epitelióide mediastinal em paciente portador de insuficiência coronária: tratamento cirúrgico simultâneo. Rev. Bras. Cir. Cardiovasc., 6(3):213-219, 1991.

crescimento e dos achados microscópicos. A elevada incidência de mitoses é, invariavelmente, característica de malignidade. Outros sinais de malignidade incluem seu tamanho, necrose e hemorragia.

No caso que relatamos, apesar do estudo imunohistoquímico da peça ter resultado negativo para marcadores de fibra muscular (HHF-35 e Desmina), o aspecto anatômico (Figura 4) e histológico (Figura 5) típico observado nos cortes do tumor permitiram o diagnóstico de leiomiossarcoma epitelióide.

O prognóstico do leiomiossarcoma está diretamente relacionado ao tamanho e penetração do tumor nas estruturas subjacentes. Em séries de leiomiossarcomas cutâneos estudadas, $40 \%$ dos tumores recidivaram localmente, porém sem ocasionar metástases ${ }^{4}$. Em leiomiossarcomas subcutâneos, cerca de $50 \%$ apresentaram recidiva e $1 / 3$ desses pacientes veio a falecer como conseqüência de suas metástases ${ }^{4}$. O prognóstico foi ainda pior naqueles tumores localizados no interior da musculatura. A maioria das metástases à distância somen- te ocorreu cerca de 15 anos após a extirpação do tumor primitivo ${ }^{10}$.

Por outro lado, SHAW et alii ${ }^{12}$ observaram $63 \%$ de sobreviventes a longo prazo, dentre 28 pacientes submetidos a ressecção de leiomiossarcomas com sede em pulmão. Esses autores observaram ausência de recidivas, ou de outras complicaçōes, nos pacientes cujo diagnóstico precoce permitiu a completa ressecção cirúrgica do tumor.

No caso que descrevemos, o emprego de um enxerto com artéria mamária e de duas pontes com veia safena proporcionou uma adequada e completa resvascularização miocárdia, especialmente considerando-se sua faixa etária (64 anos). Por outro lado, foi possível a total remoção da massa tumoral e do tecido adjacente, o que foi facilitado por sua pequena aderência a essas estruturas, e à ausência de gânglios ou outros sinais de extensão do tumor (Figura 4).

Por outro lado, a paciente foi histerectomizada

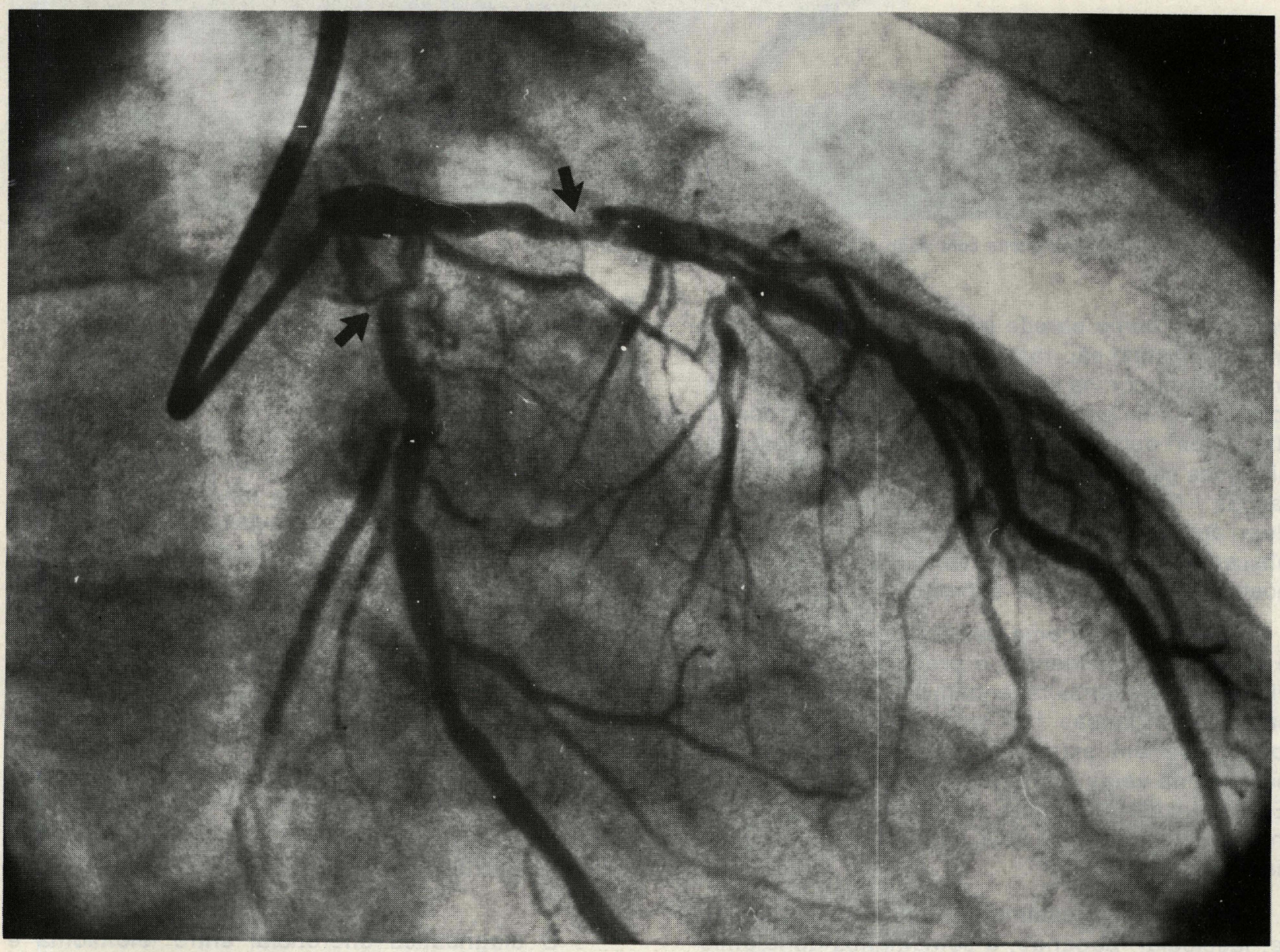

Fig. 3. - Artéria coronária esquerda, com lesões severas em seus ramos descendente anterior e circunflexa. 
DALLAN, L. A.; OLIVEIRA, S. A.; ASSIS, R. V.; SILVA, L. M.; IGLÉZIAS, J.C.R.; VERGINELLI, G.; JATENE, A.D. - Leiomiossarcoma epitelióide mediastinal em paciente portador de insuficiência coronária: tratamento cirúrgico simultâneo. Rev. Bras. Cir. Cardiovasc., 6(3):213-219, 1991.

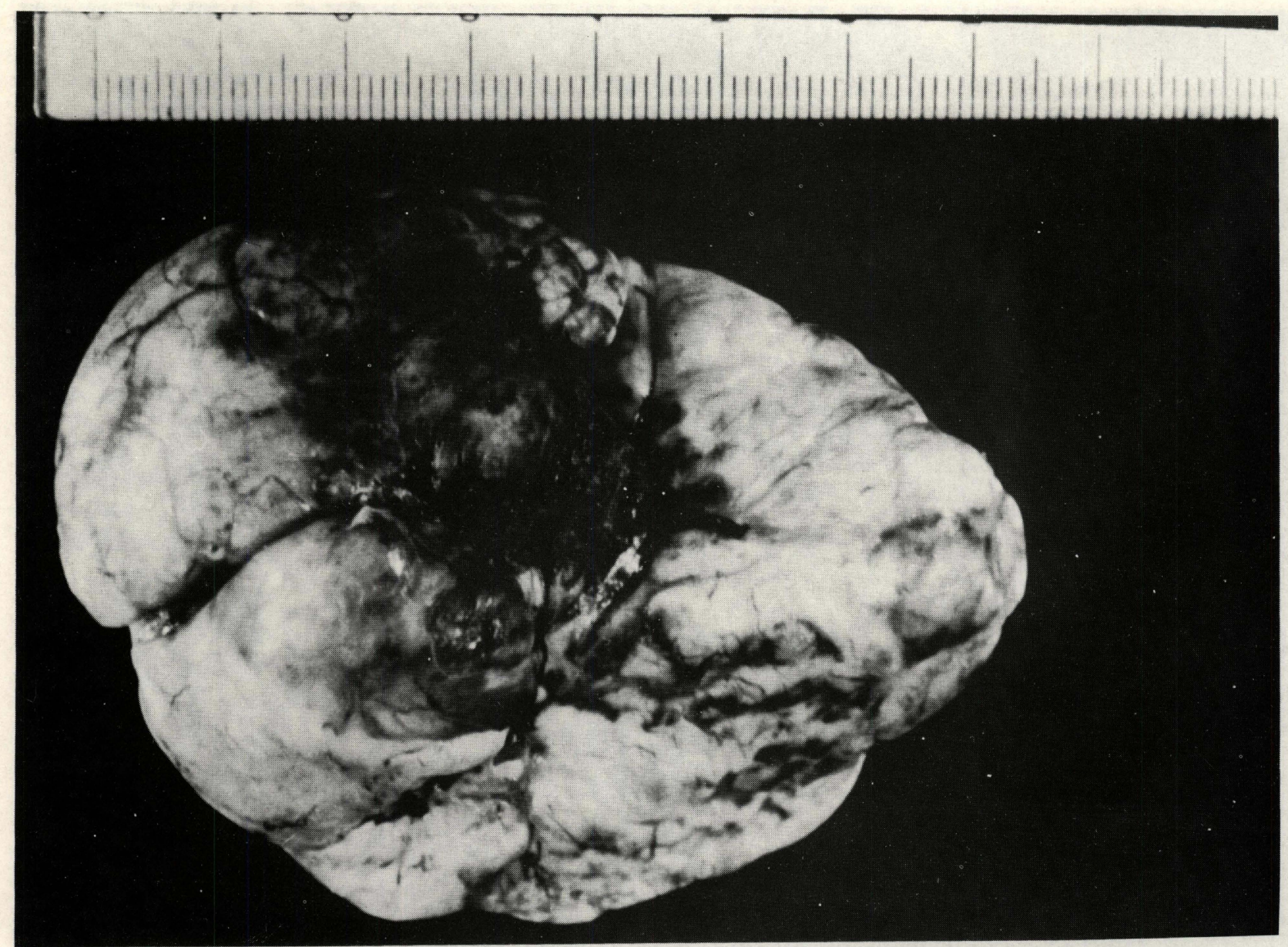

Fig. 4 - Massa tumoral ressecada do mediastino anterior.

há 13 anos, possível sede primária do tumor, período também que coincide com o surgimento de metástases, como descrito na literatura.

A paciente apresentou boa evolução pós-operatória e segue assintomática, decorridos 20 meses de pós-operatório. Entretanto, exames periódicos têm sido realizados, visando confirmar a hipótese da origem do tumor e a prevenção de outras metástases, ou eventual recidiva.

Destacamos a raridade da associação descrita e o procedimento cirúrgico que possibilitou seu tratamento simultâneo, com sucesso. 
DALLAN, L. A.; OLIVEIRA, S. A.; ASSIS, R. V.; SILVA, L. M.; IGLÉZIAS, J.C.R.; VERGINELLI, G.; JATENE, A.D. - Leiomiossarcoma epitelióide mediastinal em paciente portador de insuficiência coronária: tratamento cirúrgico simultâneo. Rev. Bras. Cir. Cardiovasc., 6(3):213-219, 1991.

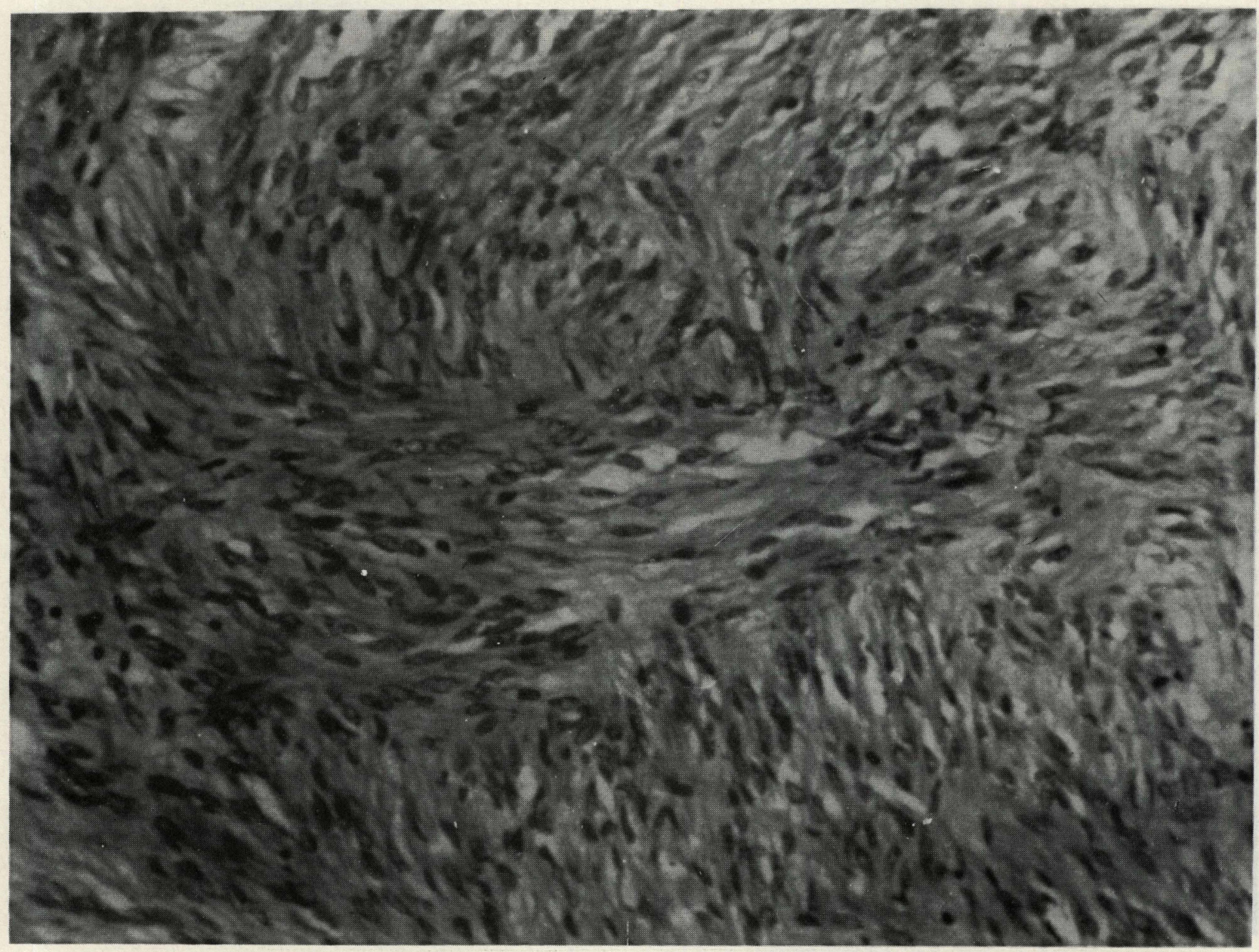

Fig. 5 - Aspecto histológico do tumor (H.E.), observando-se neoplasia constituída por células fusiformes ou ovais, de citoplasma claro e núcleo vesiculoso, com baixa atividade mitótica.

DALLAN, L. A.; OLIVEIRA, S. A.; ASSIS, R. V.; SILVA, L. M.; IGLÉZIAS, J.C.R.; VERGINELLI, G.; JATENE, A.D. - Simultaneous surgical treatment of epithelial liomyosarcoma and coronary artery insufficiency disease. Rev. Bras. Cir. Cardiovasc., 6(3):213-219, 1991.

ABSTRACT: The authors describe a case of a 64 year-old woman with a four-year history of angina. The patient was operated upon under standart cardiopulmonary bypass and had received two saphenous vein grafts and an internal mamary artery graft, concomitant with a mediastinal mass resection. The histological tumor diagnosis was epithelial leiomyosarcoma. The patient had first presented, 13 years ago, an uterine fibrosis, that had been resected. The radiograph diagnosis of the tumor was difficulted by several pleural opacities secondary to a previous pulmonary tuberculosis and a left thoracotomy. This rare association and the validity of the simultaneous surgical procedure are here emphasided.

DESCRIPTORS: myocardial revascularization + mediastinal tumor, simultaneous surgery; myorcardial revascularisation, surgery; mediastinal tumors, surgery. 
DALLAN, L. A.; OLIVEIRA, S. A.; ASSIS, R. V.; SILVA, L. M.; IGLÉZIAS, J.C.R.; VERGINELLI, G.; JATENE, A.D. - Leiomiossarcoma epitelióide mediastinal em paciente portador de insuficiência coronária: tratamento cirúrgico simultâneo. Rev. Bras. Cir. Cardiovasc., 6(3):213-219, 1991.

\section{REFERÊNCIAS BIBLIOGRÁFICAS}

1 ANTUNES, M. J.; VANDERDONCK, K. M.; ANDRADE, C. M.; REBELO, L.S - Primary cardiac leiomyosarcomas. Ann. Thorac. Surg., 51 999-1001, 1991.

2 DAHAL, I.; \& ANGERVALL, L. - Cutaneous and subcutaneous leiomyosarcoma: a clinicopathologic study of 47 patients. Pathol. Europ., 9: $307-315$, 1974.

3 DONNER, L.; DELLANEROLLE, P.; COSTA, J. Immunoreactivity of paraffin-embedded normal tissues and mesenchymal tumor for smooth muscle myosin. Am. J. Clin. Pathol., 80: 677-681, 1983.

4 FIELDS, J. P., \& HELWIG, E. B. - Leiomyosarcoma of the skin and subcutaneous tissue. Cancer, 47: 156-169, 1981.

5 LILLO-GIL, R.; ALBRECHTSON, V.; JAKOBSON, B. Pulmonary leiomyoarcoma appearing as a cyst: report of one case and review of the literature. Thorac. Cardiovasc. Surg., 33: 250-252, 1985.

6 MACKAY, B.; RO, J.; FLOYD, C.; ORDONEZ, N. G. Ultrastructural observations on smooth muscle tumors.
Ultrastruct. Pathol., 11: 593-607, 1987.

7 MALDONADO, J.; REBELO, L. S.; ANTUNES, M.; PROVIDENCIA, L.; LOPES, M. R. - Os tumores cardíacos primários: a propósito de um caso clínico. Rev. Port. Cardiol., 10: 259-262, 1991.

8 MUPHY, M. C.; SWEENWY, M. S.; PUTNAM Jr., J. B. - Surgical treatment of cardiac tumors: a 25 year experience. Ann. Thorac. Surg., 49: 612-618, 1990.

9 ROBBINS, S. L. - Pathology. Philadelphia, W. B. Saunders Company, 3. ed. 1969, cap. 4.

10 ROSAI, J. - Ackerman's surgical pathology, 1989. Vol. 2, cap. 25.

11 SALM, R.; \& EVANS, D. J. - Myxoid leiamysarcoma. Histopathology, 9: 159-169, 1985.

12 SHAW, R. R.; PAULSON, D. L.; KEE, J. L. LOVETT, V. F. - Primary pulmonary leiomyosarcomas. J. Thorac. Cardiovasc. Surg., 41: 430-436, 1961.

13 SHERON, N.; GRIFFITHS, M.; JOHNSON, N. M. Metastatic uterine leiomyosarcoma in association with recurrent lung abcess. Thorax, 44: 597-598, 1989. 